\title{
Primary Syphilis
}

National Cancer Institute

\section{Source}

National Cancer Institute. Primary Syphilis. NCI Thesaurus. Code C128412.

The subclinical or symptomatic stage of syphilis, occurring at an average of three weeks after contact with an infected individual. It manifests with one or more painless, indurated ulcers (chancres) of the skin or mucous membranes at the site of inoculation. These lesions heal spontaneously within a few weeks. 